\title{
Single-leg spica provides adequate stability after open reduction in developmental dysplasia of the hip
}

\author{
Nabil Alassaf ${ }^{1}$ \\ Received: 10 August 2017 / Published online: 16 November 2017 \\ (c) The Author(s) 2017. This article is an open access publication
}

\begin{abstract}
Introduction The late detection of developmental dysplasia of the hip (DDH) will remain a major concern in some parts of the world until effective screening programs become available. With late diagnosis comes the need for open surgical reduction. Surgery is invariably followed by a period of immobilisation in a spica cast to prevent postoperative displacement. The goal of this study is to evaluate the effect of double-leg spica as compared to single-leg spica, on the risk of displacement after unilateral open reduction of the hip.

Materials and methods This was a retrospective review of DDH patients from 2012 to 2016 and younger than 4 years of age, who had unilateral anterior open reduction. Patients who had one of the following were excluded: neuromuscular diagnosis, the addition of K-wire, and simultaneous bilateral open reductions. Demographic data were collected along with related clinical and radiographic variables. A total of 128 patients (162 hips) met the inclusion criteria; 93 were in the double-leg spica group, and 69 were in the single-leg spica group.

Results The mean age was $25.4 \pm 8.1$ months and the mean follow-up was $18.6 \pm 11.6$ months. Baseline characteristics were balanced between the two groups. There were three events of redislocation in the double-leg spica group as compared to one redislocation in the single-leg spica group. The difference did not reach statistical significance $(p=0.637$, risk ratio 1.317 , CI $0.736-2.356$ ). The difference in subsequent disruption of Shenton's line and hip migration of more than $29 \%$ was $(p=0.395$, risk ratio $1.411, \mathrm{CI} 0.892-2.234)$ and ( $p=0.087$, risk ratio 0.67 , CI $0.417-1.078)$, respectively. Three patients had a greenstick distal femur fracture after double-leg spica and one after single-leg spica.

Conclusion These data suggest that including the contralateral hip in the cast after open reduction is not essential as it does not seem to improve stability.
\end{abstract}

Keywords Developmental dysplasia of the hip · Open reduction · Hip spica $\cdot$ Single leg $\cdot$ Redislocation $\cdot$ Children

\section{Introduction}

The term developmental dysplasia of the hip (DDH) spans several pathologies ranging from acetabular dysplasia without subluxation to frank dislocation. The incidence is as high as 6.6 in 1000 live births in populations that have no clinical and/or sonographic universal screening and approximately

Electronic supplementary material The online version of this article (https://doi.org/10.1007/s00402-017-2845-1) contains supplementary material, which is available to authorized users.

Nabil Alassaf

nalassaf@kfmc.med.sa

1 Department of Surgical Specialties, King Fahad Medical City, P. O. BOX 59046, Riyadh 11525, Kingdom of Saudi Arabia
2.2 in 1000 present late, mandating operative treatment [1]. After operative reduction of developmentally dislocated hips, the child is put in a hip spica cast. When the hip undergoes closed reduction, the opposite hip is invariably included in a frog-leg position [2]. In contrast, after open reduction with or without pelvic osteotomy, the hip is placed in a more neutral position with slight abduction. Currently, there is wide variation among practicing groups on whether to include the contralateral hip after unilateral procedures. Double-leg spica (DLS) or the one-half-leg spica casting is traditionally recommended and believed to better stabilize the hip. The single-leg spica (SLS), which is sometimes referred to as a walking cast, as a proportion of children walk in the cast, is used less frequently $[3,4]$. Some practitioners extend the cast to include the toes of the affected extremity 
[5]. If delicate moulding is desired, plaster of Paris is used instead of lighter, stronger and waterproof fibreglass [6].

The superiority of SLS as compared to DLS with regard to burden on caregivers is unequivocally documented in previous publications $[4,5]$. SLS spica was found to provide adequate stability in pediatric femoral fracture, but reports examining the adequacy of SLS after DDH reduction are lacking $[3,4,7]$. The goal of this study is to evaluate the effect of double-leg spica as compared to single-leg spica, on the risk of displacement after unilateral open reduction of the hip. The study hypothesis is that patients in the DLS group would have a lower probability of postreduction hip displacement.

\section{Materials and methods}

\section{Selection of patients}

An institutional review board approved this retrospective cohort study. Operating room medical records from October 2012 to June 2016 were screened. Patients who met the following inclusion criteria were included: a radiographic diagnosis of DDH, treatment by unilateral primary anterior open reduction, the absence of known teratologic or neurological disease, and aged less than 4 years old. Patients were excluded if hips had simultaneous bilateral open reduction, a stabilising Kirschner wire (K-wire), or were lost to follow-up during cast immobilisation.

\section{Baseline data}

Electronic charts were reviewed for information related to age, sex, side, type of hip spica and severity of the disease using the International Hip Dysplasia Institute (IHDI) system [8]. Surgical notes were reviewed for evidence of open reduction and for whether pelvic or femoral osteotomies were done. Duration of cast immobilisation and duration of the follow-up were recorded from clinic visit notes.

\section{Outcome parameters}

Final follow-up frontal pelvic digital radiographs (Centricity PACS; GE Medical Systems, Slough, United Kingdom) (Fig. 1) and the clinical notes, were examined for evidence of early redislocation producing uncoverage of the femoral head during cast immobilisation, late displacement, as defined by clearly interrupted Shenton's line or a migration percentage (MP) of more than $29 \%$ as described by Riemers [9]. Information related to unplanned cast-related trips to the operating room, skin complications and insufficiency fractures secondary to immobilisation were collected.
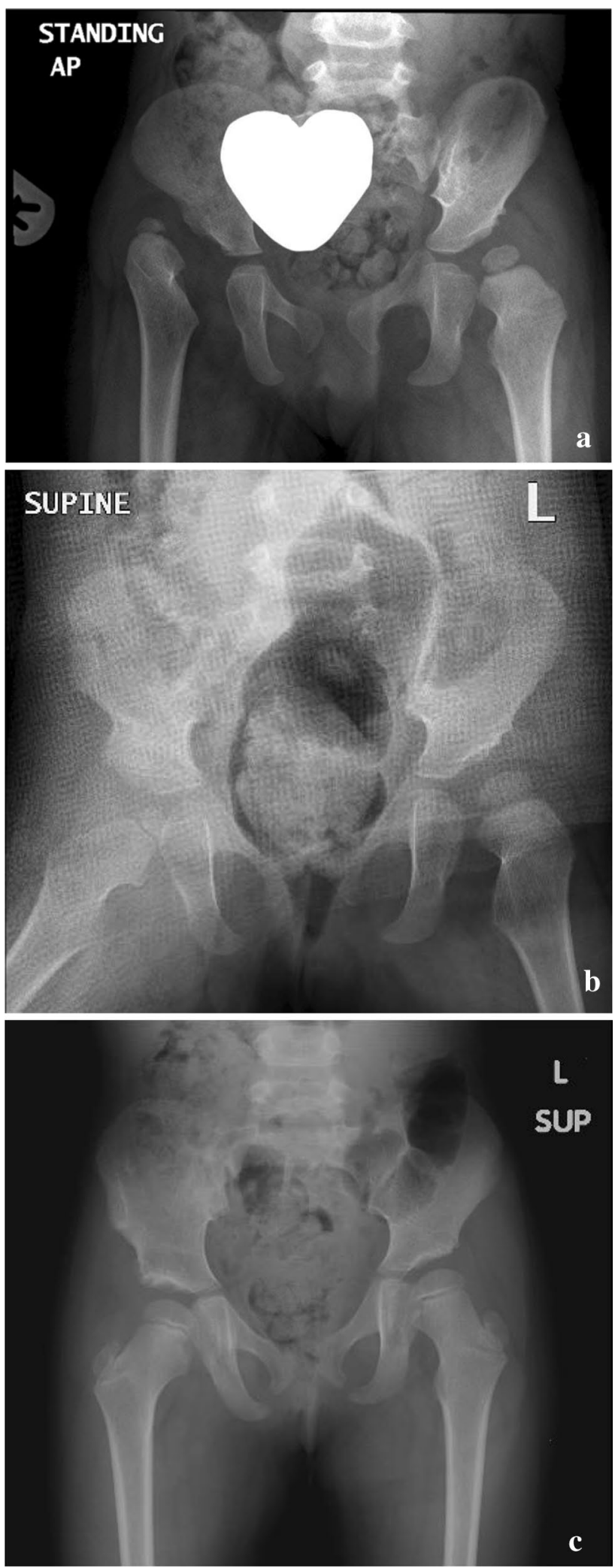

Fig. 1 a A 2-year-old girl with right hip dislocation and dysplastic left hip. b Ten weeks after right hip open reduction and acetabuloplasty. c Follow-up radiograph postoperatively at 2 years, showing maintained right hip reduction and spontaneous improvement of left hip dysplasia 


\section{Treatment pathway}

Capsular plication is done routinely after open reduction in all subjects. The type of hip spica was determined solely based on the surgeons' routine practice using standard principles [10]. Three of the attending physicians with 3-4 years of experience in treating DDH, always used DLS with a connecting bar after open reduction of DDH and the upper part of the spica is removed in the clinic to free the hips for an additional 2-3 weeks, before complete discontinuation of the cast. The fourth attending physician who was in his first year of independent practice at the beginning of the study routinely used SLS after unilateral open reduction of

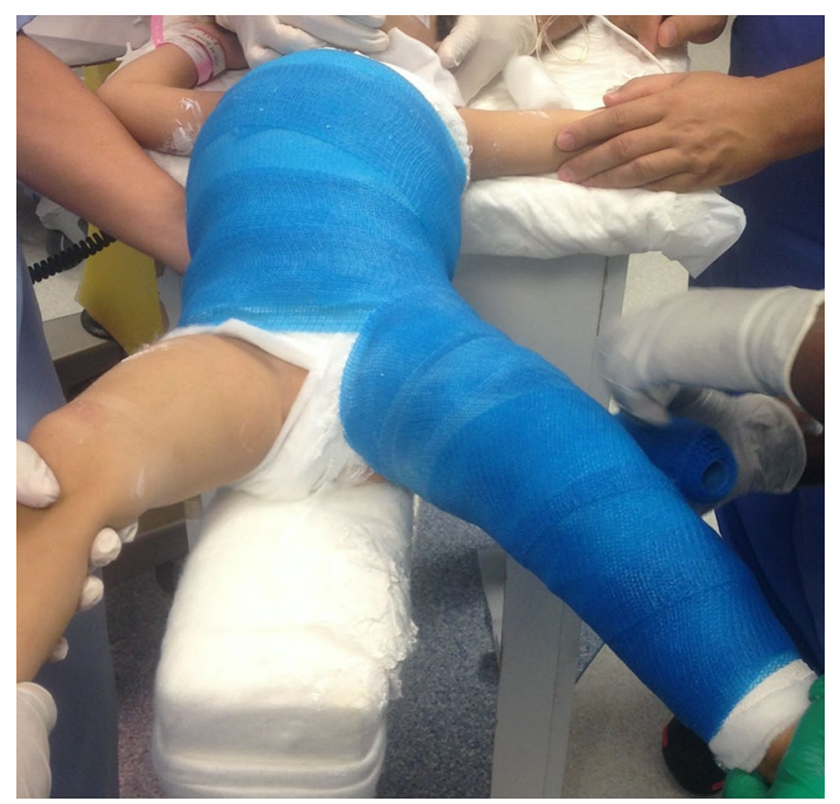

Fig. 2 Clinical picture showing a single-leg cast application, after left hip open reduction the hip with augmentation at the hip area (Fig. 2). Casting was done immediately after the procedure and under general anaesthetic on a spica frame, followed by radiographic confirmation of concentric reduction before leaving the operating room and prior to hospital discharge. Fiberglass material was used for both groups with cotton padding.

\section{Statistical analysis}

Statistical analyses were performed with R software, version 3.3.1 (R Foundation for Statistical Computing, Vienna, Austria). Normality of distribution and equality of variances were assessed graphically. Independent Student's $t$ test for parametric data and Mann-Whitney-Wilcoxon test for nonparametric data were applied when testing continuous variables. Chi-square test and Fisher's exact tests were used to test proportions. A two-sided $p$ value of 0.05 was considered significant.

\section{Results}

In total, 162 hips in 128 patients met the inclusion criteria, 104 girls and 24 boys. The mean age was $25.4 \pm 8.1$ months (range 11-48 months) and the mean follow-up duration was $18.6 \pm 11.6$ months (range $2-49$ months). Seventy-one open reductions were in the right hip and 91 involved the left hip. The baseline parameters were not different between the two groups (Table 1). The early radiographic values during cast application and immediately after were not different as well as the risk of fractures secondary to disuse osteopenia (Table 2). These fractures were invariably undisplaced occurring in the ipsilateral distal femur (Fig. 3). Three patients in the DLS cast had unplanned trips to the operating room, one for manipulation for stiffness and two were for a dirty cast and two patients in the SLS group had an

Table 1 Baseline characteristics

\begin{tabular}{|c|c|c|c|}
\hline & Double-leg spica group $(n=93)$ & Single-leg spica group $(n=69)$ & $p$ value \\
\hline Age (months), mean \pm SD (range) & $25.2 \pm 7.8(13-48)$ & $25.65 \pm 8.56(11-46)$ & 0.717 \\
\hline Female gender & $81(87.1 \%)$ & $51(74.9 \%)$ & 0.053 \\
\hline Right side & $41(44 \%)$ & $30(43.4 \%)$ & 1 \\
\hline \multicolumn{4}{|l|}{ IHDI } \\
\hline 2 & $1(1.1 \%)$ & $1(1.4 \%)$ & \multirow[t]{3}{*}{0.849} \\
\hline 3 & $12(12.9 \%)$ & $7(10.1 \%)$ & \\
\hline 4 & $80(86 \%)$ & $61(88.4 \%)$ & \\
\hline Pelvic osteotomy & $89(95.6 \%)$ & $63(91.3 \%)$ & 0.327 \\
\hline Femoral shortening & $11(11.8 \%)$ & $15(21.7 \%)$ & 0.138 \\
\hline Duration of casting (days), mean $\pm \mathrm{SD}$ (range) & $75.53 \pm 25.05(39-171)$ & $72.78 \pm 12.78(35-120)$ & 0.365 \\
\hline Duration of follow-up (months), mean \pm SD (range) & $18.85 \pm 11.90(2-48)$ & $18.36 \pm 11.19(3-49)$ & 0.794 \\
\hline
\end{tabular}

$S D$ standard deviation, IHDI International Hip Dysplasia Institute classification 
Table 2 Results

\begin{tabular}{lccccc}
\hline & $\begin{array}{l}\text { Double-leg spica } \\
\text { group }(n=93)\end{array}$ & $\begin{array}{l}\text { Single-leg spica } \\
\text { group }(n=69)\end{array}$ & $p$ value & Risk ratio & 95\% CI \\
\hline Redislocation in the cast & 3 & 1 & 0.637 & 1.317 & $0.736-2.356$ \\
Interrupted Shenton line & 4 & 1 & 0.395 & 1.411 & $0.892-2.234$ \\
MP $>29 \%$ & 11 & 16 & 0.087 & 0.671 & $0.417-1.078$ \\
Insufficiency fractures & 3 & 1 & 0.637 & 1.317 & $0.736-2.356$ \\
\hline
\end{tabular}

$C I$ confidence interval, $M P$ migration percentage
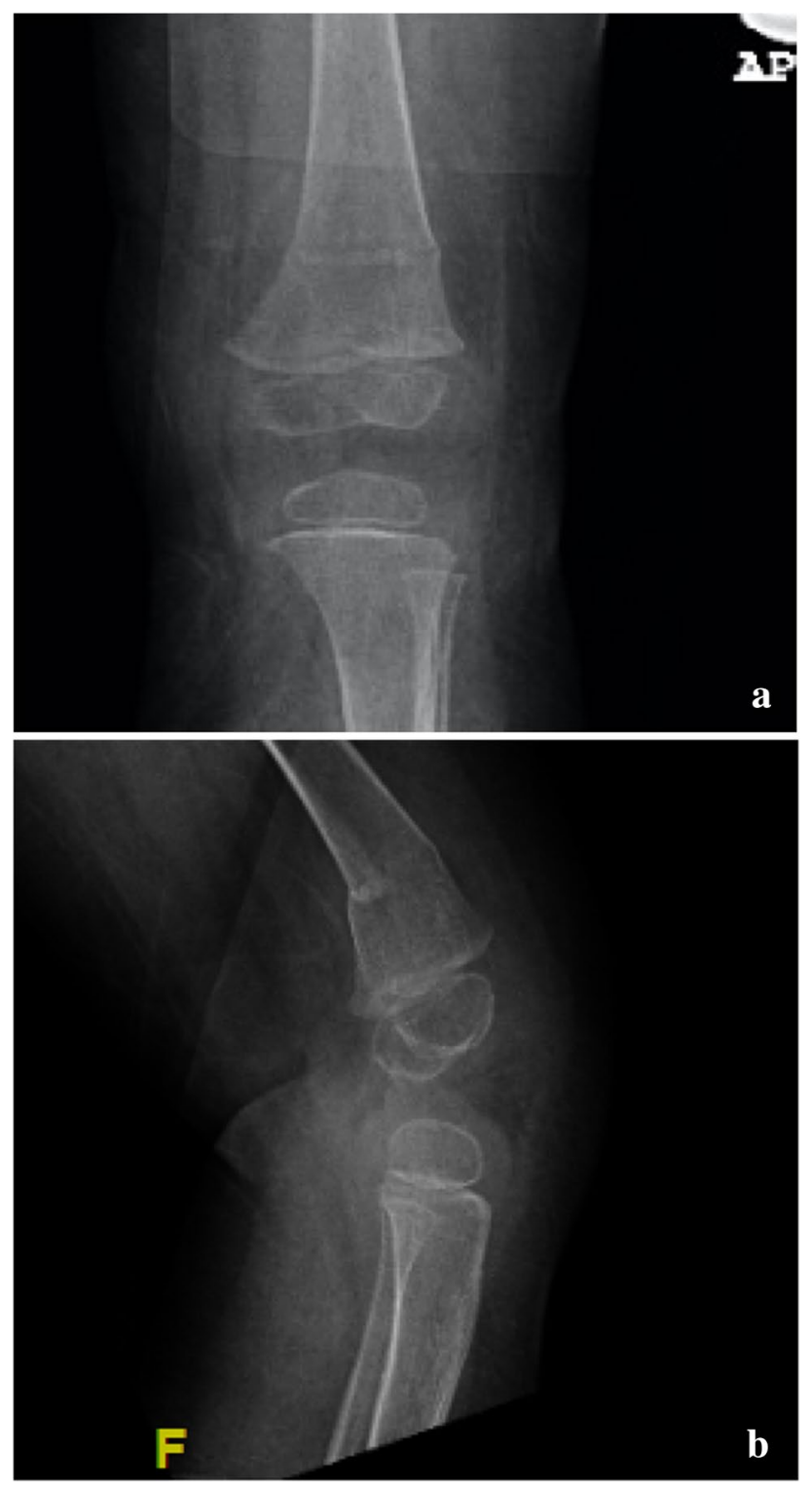

Fig. 3 a Anteroposterior and b lateral femur radiographs showing osteoporotic fracture after casting, following ipsilateral open reduction

unscheduled cast change. There were no documented incidents of cast or skin breakage requiring special wound care in both study groups.

\section{Discussion}

SLS can potentially reduce cost and operative time. The impact of caring for the child with hip spica is substantial and has been quantified in the literature, and SLS has been shown to ameliorate the burden on the family $[4,5]$. Hughes et al., examined the course of treatment on a 23 pediatric femoral fractures, where DLS was used, and they found a mean of 3 weeks of time off work by one of the working parents until adequate care arrangements could be made. The family's greatest concern was transportation [11]. In a review of 45 patients who were put on SLS for pediatric femoral fractures, Epps et al., noted that $80 \%$ of the parents had missed an average of 2 weeks from work for the care of their child, and only $50 \%$ of children continued school or daycare [3].

Historically, postoperative casting protocols for DDH varied greatly in the literature. For example, Dega used DLS for 4 weeks, then the pelvic part is cut, and after a total of 6 weeks the entire cast was removed [12]. Pemberton used DLS for 2 months without any alteration during the casting period [13]. In addition, Salter recommended 6 weeks of single-leg casting followed by 4 weeks of bilateral toe-togroin casts with an abduction bar [14]. In the present study, the redislocation rate was higher in the DLS group, but differences were not significant.

In contrast to $\mathrm{DDH}$, there are a few reports on pediatric low-energy femoral fractures comparing SLS to DLS. Jaafar et al., retrospectively reviewed their experience in a cohort of pediatric femoral fractures in 59 subjects that had SLS and compared them to 35 patients in the DLS group over a period of 4 years. The SLS group had a lower rate of leg length discrepancy. Risk of loss of reduction was similar for both casting techniques [7]. In a randomised trial of pediatric femoral fractures, Leu et al., compared 24 patients in the SLS group with 28 patients in the DLS group. The authors found statistically significant more SLS adaptability to car seats and chairs as well as less time off work for the parents. For DLS the mean time off work by caregiver, was 19 and 10 days for the SLS [5]. Earlier, in a prospective cohort by Flynn et al., 19 patients were treated with SLS and 26 were treated by DLS. There was significantly less impact on the 
family reported score and the need for ambulance transportation with SLS [4].

Four patients (3.1\%) had osteopenic fractures in this study, although this was not as common as fractures in chronically ill patients; caregivers may need to be aware of this risk. Fractures after casting for DDH are not extensively documented in the literature. Szalay and colleagues found one $z$ score drop after 4-6 weeks of postoperative immobilisation or non-weight bearing in 15 orthopaedic patients. This was based on measurements from the distal femur, and most of the bone mineral density loss was in the cancellous bone and transitional regions [15].

Stability of the hip as defined by MP was not markedly different between the two groups. Based on the original work of Reimers, in patients with neuromotor hip disorders, MP was strongly correlated with the center edge angle of Wiberg. In the same landmark paper, 355 measurements were taken from urographic studies of children with no hip disease, and the highest recorded values were $29 \%$. This cut-off value was used in the current study to indicated suboptimal femoral head coverage [9]. Careful longer-term follow-up is needed to ascertain satisfactory remodelling in hips showing higher values.

Five of the DDH patients required unscheduled trips to the operating room. In a study by DiFazio et al., 300 spica casts for pediatric femoral fractures were reviewed, and 24 patients required an unplanned trip to the operating room for cast change and 77 had skin complications [16]. None of the subjects in this study had wound care for skin ulcers, but our database is not sensitive to minor cast-related skin complications, mainly because a large proportion of the patients seek medical attention, and get cast trimming and padding at facilities near where they live.

This study has several limitations; it probably lacks adequate power to detect small differences in displacement rate between the two groups. It is somewhat assuring, however, that the redislocation rate was lower in the SLS group. Post hoc power analysis showed adequate power $(>80 \%)$ if a conventional margin of $10 \%$ was computed, but a $10 \%$ margin would be considered high by many. Stiffness was not studied as an outcome measure in this report for several reasons. These reasons were mostly due to the rarity of stiffness in children, the need for longer follow-up, inconsistent documentation and the poor reliability of current measurement tools [17].

Data presented here have a direct impact on DDH patients and their caregivers. Therefore, further research addressing the limitations of the current work is suggested. Moreover, the precise role of percutaneous pinning with casting in maintaining hip stability is unknown and the duration of immobilization remains empirical and could be elucidated in the future. In conclusion, SLS casting may be used after unilateral DDH open reduction procedures, without increasing the risk of early hip instability.

\section{Compliance with ethical standards}

Conflict of interest The author declares that he has no conflict of interest in the research. No benefits in any form have been received or will be received from a commercial party related directly or indirectly to the subject of this article.

Ethical approval All procedures in studies involving human participants were in accordance with the ethical standards of the institutional and/or national research committee and with the 1964 Declaration of Helsinki and its later amendments or comparable ethical standards.

Informed consent No patients were involved. This is a retrospective study of patients' data, and IRB approval was obtained.

Funding None.

Open Access This article is distributed under the terms of the Creative Commons Attribution 4.0 International License (http://creativecommons.org/licenses/by/4.0/), which permits unrestricted use, distribution, and reproduction in any medium, provided you give appropriate credit to the original author(s) and the source, provide a link to the Creative Commons license, and indicate if changes were made.

\section{References}

1. Pollet V, Percy V, Prior HJ (2017) Relative risk and incidence for developmental dysplasia of the hip. J Pediatr 181:202-207. https:// doi.org/10.1016/j.jpeds.2016.10.017

2. SCHWARTZ DR (1965) Acetabular development after reduction of congenital dislocation of the hip: a follow-up study of fifty hips. J Bone Jt Surg Am 47:705-714

3. Epps HR, Molenaar E, O'Connor DP (2006) Immediate single-leg spica cast for pediatric femoral diaphysis fractures. J Pediatr Orthop 26:491-496. https://doi.org/10.1097/01. bpo.0000217724.08794.e4

4. Flynn JM, Garner MR, Jones KJ et al (2011) The treatment of low-energy femoral shaft fractures: a prospective study comparing the "walking spica" with the traditional spica cast. J Bone Jt Surg Ser A 93:2196-2202. https://doi.org/10.2106/JBJS.J.01165

5. Leu D, Sargent MC, Ain MC et al (2012) Spica casting for pediatric femoral fractures. J Bone Jt Surg Am 94:1259-1264. https:// doi.org/10.2106/JBJS.K.00966

6. Daines SB, Aronsson DD, Beynnon BD et al (2014) What is the best material for molding casts in children? J Pediatr Orthop 34:743-748. https://doi.org/10.1097/BPO.0000000000000178

7. Jaafar S, Sobh A, Legakis JE et al (2016) Four weeks in a single-leg weight-bearing hip spica cast is sufficient treatment for isolated femoral shaft fractures in children aged 1 to 3 years. J Pediatr Orthop 36:680-684. https://doi.org/10.1097/ BPO.0000000000000523

8. Narayanan U, Mulpuri K, Sankar WN et al (2015) Reliability of a new radiographic classification for developmental dysplasia of the hip. J Pediatr Orthop 35:478-484. https://doi.org/10.1097/ BPO.0000000000000318

9. Reimers J (1980) The stability of the hip in children. A radiological study of the results of muscle surgery in cerebral palsy. Acta Orthop Scand Suppl 184:1-100 
10. Kumar SJ (1981) Hip spica application for the treatment of congenital dislocation of the hip. J Pediatr Orthop 1:97-99. https:// doi.org/10.1097/01241398-198101010-00014

11. Hughes BF, Sponseller PD, Thompson JD (1995) Pediatric femur fractures: effects of spica cast treatment on family and community. J Pediatr Orthop 15:457-460

12. Dega W, Król J, Polakowski L (1959) Surgical treatment of congenital dislocation of the hip in children. J Bone Jt Surg 41:920 934. https://doi.org/10.2106/00004623-195941050-00011

13. Pemberton PA (1965) Pericapsular osteotomy of the ilium for treatment of congenital subluxation and dislocation of the hip. $\mathrm{J}$ Bone Jt Surg Am 47:65-86

14. Salter RB (1966) Role of innominate osteotomy in the treatment of congenital dislocation and subluxation of the hip in the older child. J Bone Jt Surg Am 48:1413-1439
15. Szalay EA, Harriman D, Eastlund B, Mercer D (2008) Quantifying postoperative bone loss in children. J Pediatr Orthop 28:320 323. https://doi.org/10.1097/BPO.0b013e318168c75e

16. Difazio R, Vessey J, Zurakowski D et al (2011) Incidence of skin complications and associated charges in children treated with hip spica casts for femur fractures. J Pediatr Orthop 31:17-22. https:// doi.org/10.1097/BPO.0b013e3182032075

17. Owen J, Stephens D, Wright JG (2007) Reliability of hip range of motion using goniometry in pediatric femur shaft fractures. Can J Surg 50:251-255 